\title{
Retraction: Intraoperative Touch Imprint Cytological Analysis of Sentinel Lymph Nodes for the Presence of Metastases in Breast Cancer
}

To the editor: The conclusions of our 2006 article [1] were based on data later discovered to be incorrect. Therefore, we hereby retract the paper.

N. Papadopoulos, C. Simopoulos, G. Galazios, V. Limberis, C. Romanidis, M. Lambropoulou, G. Petrakis, G. Koutsougeras, D. Tamiolakis, J. Venizelos

Reference

1 Tamiolakis D, Papadopoulos N, Venizelos J, Lambropoulou M, Romanidis C, Petrakis G, Limberis V, Galazios G, Koutsougeras G, Simopoulos C: Intraoperative touch imprint cytological analysis of sentinel lymph nodes for the presence of metastases in breast cancer. Onkologie 2006;29:372-375. 